\title{
Local dew-point temperature, water vapor pressure, and millimeter-wavelength opacity at the Sierra Negra volcano
}

\author{
J. E. Mendoza-Torres, E. Colín-Beltrán, D. Ferrusca, and R. J. Contreras
}

Instituto Nacional de Astrofísica, Óptica y Electrónica, San Andrés Cholula, Mexico
e-mail: mend@inaoep.mx, edgarcb@inaoep.mx, dferrus@inaoep.mx

Received 15 October 2020 / Accepted 17 February 2021

\begin{abstract}
Aims. Some astronomical facilities are in operation at the Sierra Negra volcano (SNV), at $\sim 4.5 \mathrm{~km}$ over the sea level (o.s.1.) in Mexico. We asses whether it is possible to estimate the opacity for millimeter-wavelength observations based on the meteorological parameters at the site. A criterion for allowing astronomical observations at SNV depends on the atmospheric opacity at $225 \mathrm{GHz}$, which has to be $\tau_{225} \leq 0.30$ Nepers. The correlation of the opacity at SNV, measured with a radiometer at $225 \mathrm{GHz}, \tau_{225}$, with the local dew point temperature, $T_{\mathrm{DP}}$, the water vapor pressure, $P_{\mathrm{H} 2 \mathrm{O}}$ and the water vapor content (WVC) at $\mathrm{SNV}$ is studied with the aim to determine whether these parameters can be used to estimate the opacity at similar high-altitude locations for astronomical observations at millimeter wavelengths.

Methods. We used radiosonde data taken in various decades in Mexico City (MX) and Veracruz City (VR) to compute the WVC in $0.5 \mathrm{~km}$ altitude $(h)$ intervals from $0 \mathrm{~km}$ for VR and from $2.0 \mathrm{~km}$ for MX to $9.5 \mathrm{~km}$ o.s.l. to study the altitude profile WVC $(h)$ at SNV by interpolating data of MX and VR. We also fit exponential functions to observed $\mathrm{WVC}\left(\mathrm{WVC}_{\mathrm{obs}}(h)\right)$, obtaining a fit WVC $\left(\mathrm{WVC}_{\mathrm{ftd}}(h)\right)$. The $\mathrm{WVC}_{\mathrm{obs}}(h)$ and $\mathrm{WVC}_{\mathrm{ftd}}(h)$ were integrated, from lower limits of $h_{\text {low }}=2.5-5.5 \mathrm{~km}$ to the upper limit of $9.5 \mathrm{~km}$ as a measure of the input of $\mathrm{WVC}_{\mathrm{obs}}\left(h \geq h_{\text {low }}\right)$ to the precipitable water vapor.

Results. The largest differences between $\mathrm{WVC}_{\mathrm{obs}}$ and $\mathrm{WVC}_{\mathrm{ftd}}$ values occur at low altitudes. The input of $\mathrm{WVC}_{\mathrm{obs}}(h)$ to the precitpitable water vapor for $h \geq 4.5 \mathrm{~km}$ ranges from $15 \%$ to $29 \%$. At $4.5-5.0 \mathrm{~km}$, the input is between $4 \%$ and $8 \%$. This means that it is about a third of the WVC $(h \geq 4.5 \mathrm{~km})$. The input above our limit (from 9.5-30.0 km) is estimated with $\mathrm{WVC}_{\mathrm{ftd}}(h)$ and is found to be lower than $1 \%$. The correlation of $\tau_{225}$ with $T_{\mathrm{DP}}, P_{\mathrm{H} 2 \mathrm{O}}$, and $\mathrm{WVC}_{\mathrm{SNV}}$ takes values between 0.6 and 0.8 . A functional relation is proposed based on simultaneous data taken in 2013-2015, according to which it is possible to estimate the opacity with the $T_{\mathrm{DP}}$, $P_{\mathrm{H} 2 \mathrm{O}}$, or $\mathrm{WVC}_{\mathrm{SNV}}$ at the site.

Conclusions. With local meteorological parameters, it is possible to know whether the opacity meets the condition $\tau_{225} \leq 0.30$ Nepers, with an uncertainty of \pm 0.16 Nepers. The uncertainty is low for low opacities and increases with increasing opacity.
\end{abstract}

Key words. opacity - atmospheric effects - balloons

\section{Introduction}

The importance of the atmospheric water vapor for the climate, and in general for terrestrial life, makes it the subject of study in a variety of sciences, including astronomy (Otárola et al. 2009), meteorology, geophysics (Vogelmann \& Trickl 2008) and also weather forecasting. The study of the atmospheric water is important for all of them, particularly in the past years because of the global climate change, which is leading to a general warming. It also leads to more extreme phenomena with short timescales, for example, strong precipitations and even floods at some locations, and to the lack of water and even droughts at other sites. The amount of water vapor in the atmosphere depends on many factors that cause it to be highly variable with geographic coordinates and at different timescales, including diurnal and seasonal variations. Other timescales might be present as well. The water vapor in addition decreases with altitude, as we show below.

To integrate the water vapor content over all altitudes, the term precipitable water vapor (PWV) is commonly used. We refer to the amount of water vapor integrated between two given altitudes as water vapor content (WVC). The PWV decreases as the altitude of the lower limit of integration increases. Because the WVC decreases with altitude, the input of the WVC to the
PWV is larger at low than at high altitudes. Qin et al. (2001) found that $\sim 25 \%$ of WVC is concentrated in the first $2 \mathrm{~km}$ of the atmosphere.

Based on measurements of the WVC at different sites and different conditions, atmospheric models have been developed (Qin et al. 2001). The shapes of the altitude profiles are similar to each other, indicating that a generic function might be used to represent the altitude profile. Furthermore, it has been shown that the WVC follows a distribution with altitude that can be approximated by an exponential function.

To reduce the effect of the atmospheric opacity, some astronomical facilities are located at high altitudes above the sea level. We refer only to altitudes above sea level throughout. Nevertheless, for clarity we use the abbreviation o.s.l. for this altitude.

The opacity of the atmosphere at submillimeter and millimeter wavelengths is directly related to the PWV (Otárola et al. 2009, 2010 and Delgado et al. 1999), which plays a central role for astronomical observations from ground-based facilities. Among other conditions, the PWV depends on the altitude of the site, that is, on the integration of the WVC above the site. The thinner the atmosphere above a site, the lower the PWV. Above high-altitude sites, it tends to be lower than for low-altitude sites for two reasons. First, the length of the path of integration is shorter, and second the altitude interval that provides the higher 
WVC to the PWV (the lowest altitude range) is not included in the integration.

The PWV can be estimated by several ways, which include the use of GPS, observations from space at near- and mid -infrared (IR) bands (Marín et al. 2015), Earth-based spectral observations at water vapor lines at radio and millimeterwavelengths (Turner et al. 2007 and Cassiano et al. 2018), meteorological radiosondes (Giovanelli et al. 2001), and others (Pozo et al. 2016). Some of the methods for estimating the PWV directly take the integrated information and do not allow estimating the WVC at different altitude intervals. Some methods, including the use of meteorological balloons that carry sondes that take data of the atmospheric parameters at several altitudes, can obtain the WVC at different altitudes. This can allow us to better know the inputs to the PWV at different altitudes and consequently, to better know the causes of atmospheric opacity at submillimeter and millimeter wavelengths.

The PWV forecasting has allowed planing of observations at short wavelengths (millimeter to the infrared), making an optimal use of astronomical facilities (Hills \& Richer 2000; Pérez-Jórdan et al. 2015). Atmospheric models, validated with data of global navigation satellite systems and with PWV monitors (Pérez-Jordán et al. 2018; Turchi et al. 2018, 2020), have provided the opportunity of planning the observations and taking real-time decisions, and the models can even provide a tool for user-defined restrictions based on PWV measurements (Florian et al. 2012). Additionally, studies carried out at some astronomical sites have found that local meteorological parameters and atmospheric models allow estimating the mean PWV, giving values similar to those reported for these sites (Giordano et al. 2013). This is particular important for values of PWV $<1 \mathrm{~mm}$ in the case of IR observations and even for forecasting the background in IR (Turchi et al. 2020). All this indicates that local meteorological parameters might be used to forecast the PWV, with the aim to improve the quality of the observations.

The Sierra Negra volcano (SNV) is located at geographic coordinates $\phi_{\mathrm{SNV}}=97^{\circ} 18^{\prime} \mathrm{W}$ and $\lambda_{\mathrm{SNV}}=18^{\circ} 59^{\prime} \mathrm{N}$ ( $\phi=$ longitude, $\lambda=$ latitude) in the central region of Mexico. The Citlaltepetl volcano is located $7 \mathrm{~km}$ away from SNV. Its altitude is $5.6 \mathrm{~km}$ o.s.1. We recall that all the altitudes are given above sea level. SNV hosts some astronomical facilities that operate at altitudes of about $4.5 \mathrm{~km}$. For the performance of these facilities or for prospective new facilities at these sites, it is of particular interest to have a better knowledge of the PWV.

Several factors can affect the humidity transport from and to the central region of Mexico. One of them is the subtropical jet stream, a system of winds that blows from the Pacific Ocean arriving at the west (W) coast and traveling in the east (E) or northeast (NE) direction. The core of this stream is at about $10 \mathrm{~km}$, and its intensity varies throughout the year. It is stronger in Boreal Winter and Spring and weaker in the Summer. At about $160 \mathrm{~km} \mathrm{~W}$ of SNV, an active volcano is located at an altitude of $5.4 \mathrm{~km}$ o.s.l., the Popocatépetl. It expels hot clouds of steam and dust, which can also affect the flow of air currents and the humidity in the region. It can even reach the region of SNV.

The altitude profile of the WVC at SNV has not been studied, and the humidity content at different heights is not known. We analyzed the WVC at SNV based on radiosondes data obtained from stations in Mexico City (MX) and Veracruz City (VR) to determine the altitude profile and its variations throughout the year and to decide whether meteorological measurements at the site can be used to estimate the opacity at millimeter wavelengths.
We used radiosonde data of the University of Wyoming to build the altitude profile (we refer to the altitude with $h$ for the numerical processing) $\mathrm{WVC}_{\mathrm{obs}}(h)$ for $\mathrm{MX}$ and VR. With this information, we can calculate a complete altitude profile from the sea level to the maximum altitudes reached by the balloons. Additionally, we used meteorological and radiometric data from the Large Millimeter Telescope (Ferrusca \& Contreras 2014; Zeballos et al. 2016) at $225 \mathrm{GHz}$ at the SNV summit to asses whether local meteorological parameters can be used to estimate the opacity at millimeter wavelengths, as described below. The analysis is intended to establish some basis to estimate $\tau_{225}$ based on local parameters. We computed $T_{\mathrm{DP}}, P_{\mathrm{H} 2 \mathrm{O}}$, and the WVC based on the temperature $(T)$ and relative humidity (RH) with the aim to use the coefficients given in Eqs. (7)-(9) together with values that we fit to the observations (as we show in Tables 7 and 8) for this estimation.

\section{Analysis of radiosonde data}

The temperature of the dew point for each altitude $T_{\mathrm{DP}}(h)$ can be estimated according to Lawrence (2005) using the RH and $T$,

$T_{\mathrm{DP}}=\frac{\left.B_{1}\left[\ln \left(\frac{\mathrm{RH}}{100}\right)+\frac{A_{1} T}{B_{1}+T}\right)\right]}{A_{1}-\ln \left(\frac{\mathrm{RH}}{100}\right)-\frac{A_{1} T}{B_{1}+T}}$,

where $T$ is given in degrees Celsius, $\mathrm{RH}$ in percent, $A_{1}=17.625$ is a dimensionless constant, and $B_{1}=243.04^{\circ} \mathrm{C}$ is also a constant. With these values, the water vapor pressure $\left(P_{\mathrm{H}_{2} \mathrm{O}}(h)\right)$ may be computed (Alduchov \& Eskridge 1996) as follows:

$P_{\mathrm{H}_{2} \mathrm{O}}=6.1094 \exp \left(\frac{17.625 T_{\mathrm{DP}}}{T_{\mathrm{DP}}+243.04}\right)$,

where $T_{\mathrm{DP}}$ is given in degrees Celsius and $P_{\mathrm{H}_{2} \mathrm{O}}$ in millibar.

In the case of sondes, the computation can be made for each given altitude at which data are available. With the local temperature at the altitude $h, T(h)$, the pressure $P_{\mathrm{H}_{2} \mathrm{O}}(h)$, and the ideal-gas law, it is then possible to estimate the number density of water vapor molecules at each altitude, $n_{\mathrm{w}}(h)$.

The volume density of water vapor molecules at a given altitude, $\rho(h)$, is the product of the number density, $n_{\mathrm{w}}(h)$, and the mass of the water molecule, which is $18 \mathrm{amu}$ or $2.99 \times 10^{-23} \mathrm{~g}$. The mass $M$ of a column of water vapor between two different altitudes can be estimated using $\rho(h)$ at a given altitude. The width of the altitude interval may be considered as the length of the column. The volume of this column is then computed for the given altitude. The mass of the water vapor in a column between two altitudes is obtained by multiplying the volume of the column and the average volume density between the two given altitudes. The total mass of a column is obtained by integrating over all the altitudes. Finally, using the mass of the water vapor column and the density for liquid water $\left(1 \mathrm{~g} \mathrm{~cm}^{-3}\right)$, the column of liquid water equivalent to the column of water vapor is computed.

Meteorological sondes in balloons take in situ measurements of $T(h), P(h)$, and RH $(h)$, typically from altitudes of some dozen meters above the surface of the site of release up to the altitudes that are attained by the balloons (typically $\sim 9-10 \mathrm{~km}$ ). Nevertheless, it is important to comment that in this method, the sondes do not take data at a certain height, but at a fixed time. In locations where wind is present, the instruments therefore take data at quasi-random increased positions either in height and/or horizontal directions. To obtain a number every $500 \mathrm{~m}$ (or $0.5 \mathrm{~km}$ ) for comparison among different cities, we therefore interpolated 
the measurement with data taken at altitudes within above $0.5 \mathrm{~km}$ this. When no data are available within these $0.5 \mathrm{~km}$ ranges on one day, this day is omitted from the analysis.

\subsection{Radiosondes at Sierra Negra}

Meteorological sondes have been released at noon $(12 \mathrm{~h}$ local time) and midnight ( $0 \mathrm{~h}$ local time), in Mexico City since 1973 and in Veracruz City since 1982. Mexico City is located at $2.2 \mathrm{~km}$ o.s.1. with coordinates $\phi_{\mathrm{MX}}=99^{\circ} 7^{\prime} \mathrm{W}$ and $\lambda_{\mathrm{MX}}=19^{\circ}$ $25^{\prime} \mathrm{N}$, which is about $200 \mathrm{~km} \mathrm{~W}$ of SNV, whereas Veracruz is at sea level, with coordinates $\phi_{\mathrm{VR}}=96^{\circ} 8^{\prime} \mathrm{W}$ and $\lambda_{\mathrm{VR}}=19^{\circ} 10^{\prime}$ $\mathrm{N}$, about $120 \mathrm{~km}$ E of SNV.

Balloons travel about $50-100 \mathrm{~km}$ in horizontal direction. Predicting wind directions at different height and space scales is complicated (Carreón-Sierra et al. 2015; Thomas et al. 2020), but the balloons of both stations are expected of taking data of regions around the Sierra Negra during their flights.

The WVC is estimated at a series of altitudes at MX and VR. In other cases, a similar approach was taken with the aim to compare the altitude profiles for different sites (Qin et al. 2001). In our case, the WVC is estimated at fixed altitudes $\left(h_{i}\right)$ at two sites to allow estimating the WVC at a third site for the same series of altitudes, which extend from 2.0 to $9.0 \mathrm{~km}$ at $0.5 \mathrm{~km}$ each.

The process of estimating the WVC begins by selecting lowand a high-altitude limits with a difference of $0.5 \mathrm{~km}$. As an example, the WVC for the 3.5 and $4.0 \mathrm{~km}$ limiting altitudes was estimated by fitting the values of $\rho$ inside this interval to a straight line function. The density for $3.75 \mathrm{~km}$ was computed with the linear function, and based on this and a column of $0.5 \mathrm{~km}$ height, the WVC $\left(h_{i}\right)$ was computed (Sect. 2$)$. For an altitude interval higher by $0.5 \mathrm{~km}$ (i.e., $4.0-4.5 \mathrm{~km}$ ) another linear fit was made and the density for $4.25 \mathrm{~km}$ was computed. The density at this altitude was used for the estimate, again considering a column of $0.5 \mathrm{~km}$ height.

\subsection{Estimation of the WVC at SNV by interpolating WVC at $M X$ and $V R$}

The estimation of the WVC at SNV is based on the measurements made at MX and VR. The WVC at common altitudes for both sites were used to estimate the WVC at the same altitudes for SNV because in this case, it is possible to proceed for other sites of interest with similar conditions. We use a method as follows:

First, using the geographic coordinates of $\mathrm{MX}$ as reference, we computed $\Delta \phi=\phi_{\mathrm{VR}}-\phi_{\mathrm{MX}}=-2.9833^{\circ}$ and $\Delta \lambda=$ $\lambda_{\mathrm{VR}}-\lambda_{\mathrm{MX}}=-0.2500^{\circ}$. Because these differences are small, we visualized their locations in a two-dimensional geometry. The straight imaginary line that joins MX and VR has a slope with respect to the EW direction that is given by $m_{\mathrm{MX}-\mathrm{VR}}=\Delta \lambda / \Delta \phi$. Then, the MX-VR line (taking MX as the origin) is simply $\Delta \lambda=m_{\mathrm{MX}-\mathrm{VR}} \Delta \phi$, with $m_{\mathrm{MX}-\mathrm{VR}}=0.0838$. Second, the SNV coordinates do not lie on the MX-VR line. However, the line passes near SNV. To identify the coordinates of the closest point to this line, another line perpendicular to it that crosses SNV was determined. The slope of this line was $m_{\mathrm{SNV}}=-1 / m_{\mathrm{MX}-\mathrm{VR}}$ and the line (also with respect to $\mathrm{MX}$ ) is $\Delta \lambda=A+m_{\mathrm{MX}-\mathrm{VR}} \Delta \phi$, with $A=-22.1122^{\circ}$ and $\mathrm{m}_{\mathrm{MX}-\mathrm{VR}}=-11.9333$. Then, the coordinates of the intersection point $\mathrm{SNV}^{\prime}$ of these lines are $\left(97^{\circ} 17^{\prime} \mathrm{W}, 19^{\circ}\right.$ $\left.16^{\prime} \mathrm{N}\right)$. Third, these two points describe the process with which we calculated the coordinates of the location between MX and VR that is closest to SNV, which is SNV'. Then, the WVC at
$\mathrm{SNV}^{\prime}$ may be estimated by interpolating the WVC at MX and VR. It is possible to do this using the distance from MX on the $\mathrm{MX}-\mathrm{VR}$ line to $\mathrm{SNV}^{\prime}$. For $\mathrm{SNV}^{\prime}$ and $\mathrm{MX}, \Delta \phi=-1.8167^{\circ}$ and $\Delta \lambda=-0.4333^{\circ}$. The total geographic angular distance between $\mathrm{SNV}^{\prime}$ and $\mathrm{MX}$ is $\Delta \theta=\left(\Delta \phi^{2}+\Delta \lambda^{2}\right)^{1 / 2}=1.8677^{\circ}$.

For each height $h_{i}$ from 2.0 to $9.0 \mathrm{~km}$ (the altitude range for which we estimated the WVC values at MX and VR), we fit a straight line function for the WVC. The WVC for SNV' was computed with $\operatorname{WVC}\left(h_{i}\right)=A\left(h_{i}\right)+B\left(h_{i}\right) \Delta \theta$, where $A\left(h_{i}\right)$ and $B\left(h_{i}\right)$ are the coefficients for each height $h_{i}$. We refer to the WVC estimated in this way for $\mathrm{SNV}$ as $\mathrm{WVC}_{\mathrm{obs}}(h)$.

\subsection{Description of the WVC altitude profile with an exponential function}

The density of a given molecular species at the altitude in the atmosphere, $N(h)$, can be approximated with the assumption that the atmosphere is in hydrostatic equilibrium. The WVC $(h)$ can also be fit by exponential functions as follows:

$\mathrm{WVC}_{\mathrm{ftd}}(h)=\mathrm{WVC}_{0} e^{-h / h_{0}}$,

where $\mathrm{WVC}_{0}$ is the content at the base and $h_{0}$ is the scale height, that is, the altitude at which the density takes the value $\mathrm{WVC}_{0} / e$, which is approximately $\mathrm{WVC}_{0} / 3$. The larger $h_{0}$, the slower the decay of the $\mathrm{WVC}_{\mathrm{ftd}}$ with altitude. The coefficient $\mathrm{WVC}_{\mathrm{ftd}}(h)$ determines the WVC values in the altitude profile.

Exponential functions were fit to the $\mathrm{WVC}_{\mathrm{obs}}$ profiles of $\mathrm{MX}$, $\mathrm{VR}$, and SNV to estimate the coefficients $\mathrm{WVC}_{0}$ and $h_{0}$ given in Eq. (3). We recall that to compute the $\mathrm{PWV}_{\mathrm{obs}}$, the integration has a minimum possible altitude of $2.0 \mathrm{~km}$ for the SNV.

\section{Results and discussion}

In Fig. 1 the $\mathrm{PWV}_{\mathrm{obs}}(h)$ observed at $\mathrm{MX}$ is plotted against the same quantity observed at VR when simultaneous measurements were made at both stations. Figure 1 shows a high correlation between the $P W V_{\text {obs }}$ at MX and VR. The PWV $\mathrm{Ptd}_{\text {ftd }}$ and $\mathrm{PWV}_{\mathrm{obs}}$ averaged over each month of the year were also computed, integrating in both cases from 2.0 to $9.5 \mathrm{~km}$ (Table 1). We also computed their ratios (Cols. 4 and 7 of Table 1). The integration of $\mathrm{WVC}_{\mathrm{ftd}}(h)$ to compute the PWV leads to values that do not considerably differ from those computed with $\mathrm{WVC}_{\mathrm{obs}}(h)$. The difference takes values between 2 and $22 \%$ relative to the $\mathrm{PWV}_{\mathrm{obs}}$.

In Figs. 2 and 3 we show the $\mathrm{WVC}_{\mathrm{obs}}$ measured at altitude intervals $2.0-2.5$ and $4.5-5.0 \mathrm{~km}$ for MX, VR, and SNV data in 2015 . The $\mathrm{WVC}_{\mathrm{obs}}(h)$ varies with time. In Figs. 4 and 5 the $\mathrm{WVC}_{\mathrm{obs}}(h)$ profiles obtained by averaging on a monthly basis over the entire sample are shown against time for MX, VR, and SNV.

In Tables 2 and 3 the $\mathrm{WVC}_{\mathrm{ftd}} / \mathrm{WVC}_{\mathrm{obs}}$ ratios for altitude intervals of $0.5 \mathrm{~km}$ width are given. The altitude limits are given in the top rows. The ratios at about unity, showing that the fitted values are similar to the observed ones at the different altitudes. At some altitude intervals higher than $5.5 \mathrm{~km}$, the ratio is equal to unity up to two decimals for some months. This means that within two decimal numbers, the values of $\mathrm{WVC}_{\mathrm{ftd}}$ and $\mathrm{WVC}_{\mathrm{obs}}$ at these month-altitude intervals are the same. Figures 4 and 5 also show that the $\mathrm{WVC}_{\text {obs }}$ takes values lower than $2 \mathrm{~mm}$ above $4.5-5.0 \mathrm{~km}$. For example, for $h \geq 7 \mathrm{~km}$, the value is $\leq 0.5 \mathrm{~mm}$ and for $9.0-9.5 \mathrm{~km}$, it is $0.1 \mathrm{~mm}$. Taking this and the values of the ratios in Tables 2 and 3 into account, it is clear that they are the result of dividing two small quantities. The differences between $\mathrm{WVC}_{\mathrm{ftd}}$ and $\mathrm{WVC}_{\mathrm{obs}}$ are therefore expected to be even 

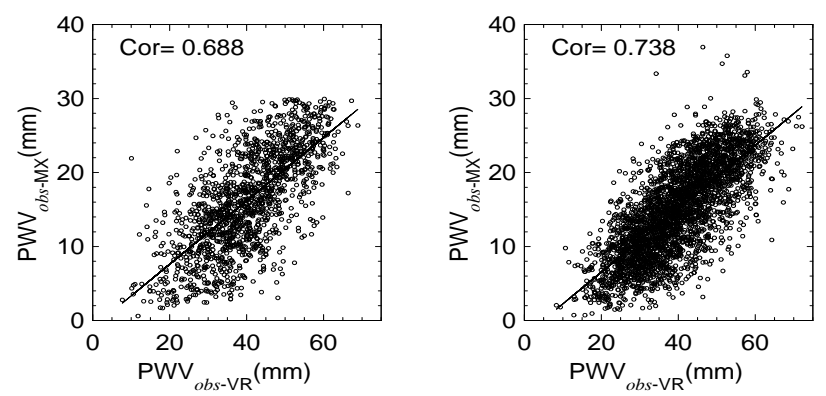

Fig. 1. Scatter plots of the PWV for data of the MX and VR stations that were obtained at the same day and time. Left panel: data taken at $0 \mathrm{~h}$. Right panel: data taken at $12 \mathrm{~h}$. The label in the upper left corner of each panel indicates the correlation between the two data sets.

Table 1. Observed and fitted PWV integrated from $2.0 \mathrm{~km}$ to $9.5 \mathrm{~km}$ for SNV for $0 \mathrm{~h}$ and $12 \mathrm{~h}$.

\begin{tabular}{lccccccc}
\hline \hline & \multicolumn{3}{c}{$0 \mathrm{~h}$} & & & \multicolumn{3}{c}{$12 \mathrm{~h}$} \\
\cline { 2 - 4 } \cline { 6 - 7 } Time & $\mathrm{PWV}_{\mathrm{obs}}$ & $\mathrm{PWV}_{\mathrm{ftd}}$ & $\mathrm{PWV}_{\mathrm{ftd}}$ & $\mathrm{PWV}_{\mathrm{obs}}$ & $\mathrm{PWV}_{\mathrm{ftd}}$ & $\mathrm{PWV}_{\mathrm{ftd}}$ \\
\hline Jan & 13.9 & 14.3 & 1.03 & & 9.5 & 8.8 & 0.93 \\
Feb & 10.5 & 12.6 & 1.20 & & 9.7 & 9.5 & 0.98 \\
Mar & 12.6 & 15.3 & 1.22 & & 9.9 & 9.8 & 0.98 \\
Apr & 15.0 & 17.4 & 1.16 & & 12.7 & 13.6 & 1.07 \\
May & 20.5 & 21.2 & 1.03 & & 15.3 & 15.8 & 1.03 \\
Jun & 18.8 & 23.0 & 1.22 & & 19.0 & 20.6 & 1.08 \\
Jul & 22.0 & 25.0 & 1.14 & & 19.6 & 20.7 & 1.05 \\
Aug & 21.4 & 26.1 & 1.22 & & 19.6 & 21.6 & 1.10 \\
Sep & 22.7 & 26.0 & 1.15 & & 21.5 & 23.6 & 1.10 \\
Oct & 21.2 & 23.3 & 1.10 & & 19.2 & 20.3 & 1.06 \\
Nov & 18.7 & 20.5 & 1.10 & & 15.1 & 16.2 & 1.07 \\
Dec & 16.5 & 15.0 & 0.91 & & 11.2 & 10.8 & 0.97 \\
\hline
\end{tabular}
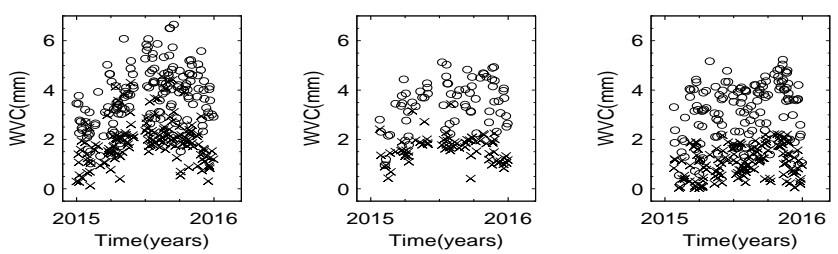

Fig. 2. WVC against time for $2.0-2.5 \mathrm{~km}$ (circles) and $4.5-5.0 \mathrm{~km}$ (crosses) for $0 \mathrm{~h}$. Left panel: observed at MX, middle panel: computed from MX and VR for SNV, and right panel: observed at VR.
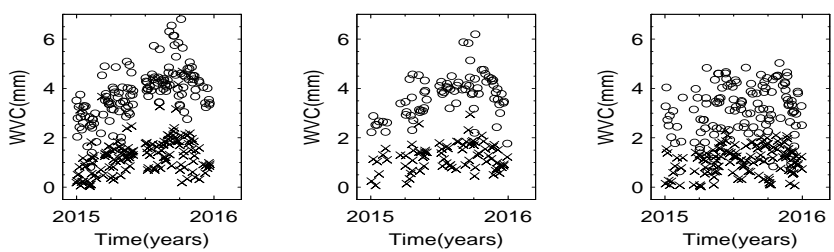

Fig. 3. Same as Fig. 2 for data at $12 \mathrm{~h}$. Left panel: for MX, middle panel: for SNV, and right panel: for VR.

lower than $0.1 \mathrm{~mm}$ for altitude intervals with a width of $0.5 \mathrm{~km}$ at $h \geq 9.5 \mathrm{~km}$, and it is feasible to use the $f t d$ values to estimate WVC for altitudes higher than $9.5 \mathrm{~km}$.

The relative input of $\mathrm{WVC}_{\mathrm{obs}}(h)$ from a given altitude interval with lower limit $h_{\text {low }}$ and higher limit equals $9.5 \mathrm{~km}$,
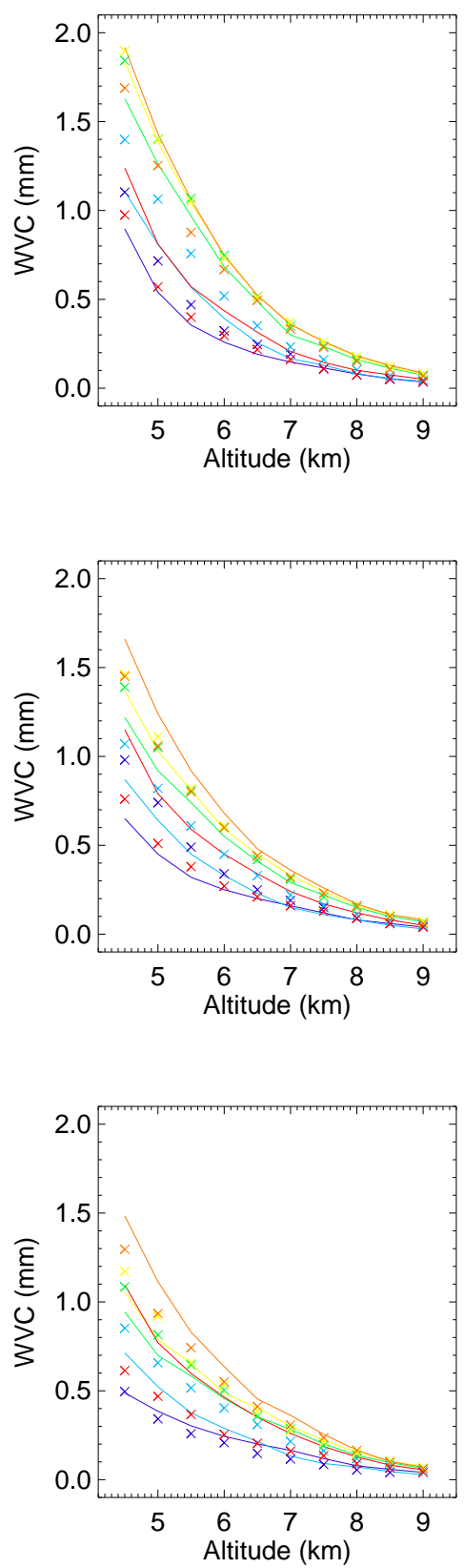

Fig. 4. Altitude profiles of the WVC averaged for each month based on the entire data set taken at $0 \mathrm{~h}$. The dark blue line is for January, the dark blue crosses for February, the light blue line for March, and the light blue crosses for April. The same type of plot shows the next months, May (line) and June (crosses) in green, July (line) and August (crosses) in yellow, September (line) and October (crosses) in orange, and November (line) and December (crosses) in red. Upper panel: observed for MX, middle panel: as obtained from MX and VR for SNV, and lower panel: observed for VR.

$\mathrm{WVC}_{\text {obs }}\left(h \geq h_{\text {low }}\right) / \mathrm{PWV}_{\text {obs }}$, is plotted against $\mathrm{WVC}_{\mathrm{ftd}}(h \geq$ $\left.h_{\text {low }}\right) / \mathrm{PWV}_{\text {ftd }}$, for $h_{\text {low }}=2.5,3.0,3.5,4.0,4.5,5.0$, and 5.5 $\mathrm{km}$ in Figs. 6 and 7. The symbol sizes grow with increasing months. The straight line has slope of unity and intersects the $y$-axis at $x=0$. If the ratios of the fitted values were equal to the observed values, they would appear above this line. Deviations of the relative fitted values with respect the observed ones are visible. For low $h_{\text {low }}$ limits, the ratios appear below the straight line and deviate more from it than the values for high $h_{\text {low }}$ limits. The largest deviations take place at the lowest 

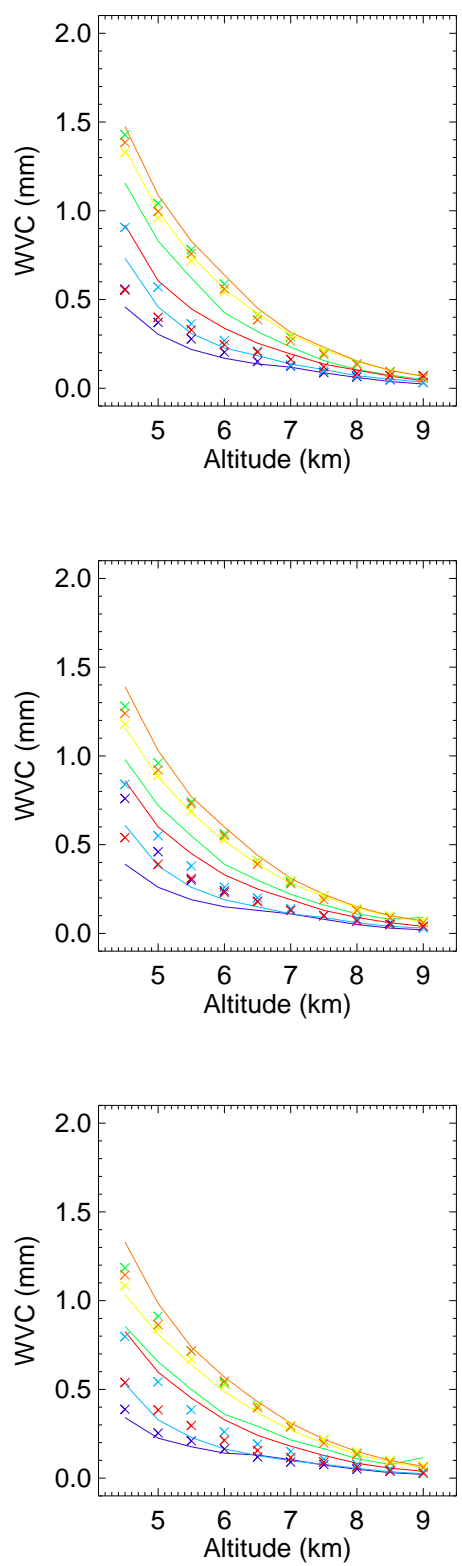

Fig. 5. Same as Fig. 4 for data taken at $12 \mathrm{~h}$. Upper panel: for MX, middle panel: for SNV, and lower panel: for VR.

altitude (upper left panel in Figs. 6 and 7). For high $h_{\text {low }}$ limits, the ratios are closer to the straight line than for low $h_{\text {low }}$ limits. This indicates that the difference between $\mathrm{WVC}_{\mathrm{ftd}}(h)$ and $\mathrm{WVC}_{\mathrm{obs}}(h)$ is smaller for high altitudes than for low altitudes. For low $h_{\text {low }}$ the values are more clumped in a region of the plot than for high values of the low limit. On the other hand, for high $h_{\text {low }}$ values the ratios are more regularly distributed along the straight line. The largest and smallest symbols appear closer to the straight line than medium-size symbols (we recall that the symbol sizes increase with increasing months), indicating that for boreal Winter, the $\mathrm{WVC}_{\mathrm{ftd}}\left(h \geq h_{\text {low }}\right)$ represents the observed values $\mathrm{WVC}_{\text {obs }}\left(h \geq h_{\text {low }}\right)$ better than for the other seasons of the year. Even though for the other seasons the deviations are larger in general, the largest deviations of these values are smaller than $20 \%$. For $h_{\text {low }}=4.5 \mathrm{~km}$, the altitude of SNV, the largest difference between the ratios (observed and fitted), is $\leq 15 \%$ (Figs. 6 and 7). This means that for high altitudes, the $f t d$ values are well approximated to the observed ones for all the months.
Table 2. Ratio of fitted and observed WVC, $\mathrm{WVC}_{\mathrm{ftd}}(\mathrm{h})$ and $\mathrm{WVC}_{\mathrm{obs}}(\mathrm{h})$, respectively, for $\mathrm{SNV}$ at $0 \mathrm{~h}$.

\begin{tabular}{llllllllllll}
\hline \hline & \multicolumn{10}{c}{$h(\mathrm{~km})$} \\
\cline { 2 - 11 } & 4.5 & 5.0 & 5.5 & 6.0 & 6.5 & 7.0 & 7.5 & 8.0 & 8.5 & 9.0 \\
Time & 5.0 & 5.5 & 6.0 & 6.5 & 7.0 & 7.5 & 8.0 & 8.5 & 9.0 & 9.5 \\
\hline Jan & 1.20 & 1.28 & 1.24 & 1.11 & 0.91 & 0.76 & 0.75 & 0.85 & 1.00 & 1.06 \\
Feb & 1.11 & 1.24 & 1.12 & 1.09 & 1.10 & 1.04 & 0.95 & 0.92 & 1.00 & 0.10 \\
Mar & 0.95 & 1.09 & 1.14 & 1.12 & 1.02 & 1.00 & 0.88 & 0.95 & 1.02 & 0.97 \\
Apr & 0.88 & 0.96 & 1.00 & 1.05 & 0.98 & 1.00 & 1.00 & 0.90 & 1.03 & 1.23 \\
May & 0.94 & 0.96 & 0.95 & 1.00 & 0.98 & 1.00 & 1.03 & 1.13 & 1.16 & 0.77 \\
Jun & 0.94 & 0.94 & 0.91 & 0.90 & 0.92 & 0.97 & 1.00 & 1.12 & 1.30 & 1.25 \\
Jul & 1.00 & 0.99 & 0.96 & 0.95 & 0.95 & 1.00 & 1.00 & 1.13 & 1.19 & 1.49 \\
Aug & 0.99 & 0.98 & 0.95 & 0.93 & 0.91 & 0.93 & 1.00 & 1.13 & 1.19 & 1.27 \\
Sep & 0.92 & 0.93 & 0.93 & 0.89 & 0.90 & 0.95 & 1.00 & 1.09 & 1.22 & 1.30 \\
Oct & 0.92 & 0.92 & 0.86 & 0.84 & 0.88 & 0.91 & 1.00 & 1.09 & 1.16 & 1.30 \\
Nov & 0.98 & 1.03 & 1.00 & 1.00 & 0.96 & 0.92 & 0.98 & 1.04 & 1.14 & 1.24 \\
Dec & 1.17 & 1.18 & 1.08 & 1.06 & 0.99 & 1.00 & 0.95 & 0.99 & 1.01 & 0.92 \\
\hline
\end{tabular}

Notes. The lower altitude interval is indicated in the highest row of each column and the upper altitude in the next row.

Table 3. Ratio of fitted and observed WVC for SNV at $12 \mathrm{~h}$.

\begin{tabular}{llllllllllll}
\hline \hline & \multicolumn{10}{c}{$h(\mathrm{~km})$} \\
\cline { 2 - 10 } & \multicolumn{10}{c}{$\mathrm{WVC}_{\mathrm{ftd}} / \mathrm{WVC}_{\text {obs }}$} \\
\hline Time & 5.0 & 5.5 & 6.0 & 6.5 & 7.0 & 7.5 & 8.0 & 8.5 & 9.0 & 9.5 \\
\hline Jan & 1.01 & 1.08 & 1.12 & 1.07 & 0.99 & 0.92 & 0.91 & 1.01 & 1.00 & 1.11 \\
Feb & 0.89 & 0.97 & 1.00 & 0.97 & 0.92 & 0.84 & 1.00 & 1.08 & 1.16 & 1.11 \\
Mar & 0.87 & 0.86 & 0.89 & 0.88 & 0.91 & 1.01 & 1.00 & 1.00 & 1.16 & 1.40 \\
Apr & 0.80 & 0.79 & 0.80 & 0.82 & 0.85 & 0.96 & 1.00 & 1.10 & 1.14 & 1.39 \\
May & 0.88 & 0.89 & 0.85 & 0.88 & 0.91 & 0.99 & 1.00 & 1.13 & 1.30 & 1.43 \\
Jun & 0.90 & 0.89 & 0.85 & 0.85 & 0.91 & 0.91 & 1.00 & 1.04 & 1.16 & 1.23 \\
Jul & 0.92 & 0.93 & 0.90 & 0.93 & 0.93 & 0.96 & 1.00 & 1.14 & 1.25 & 1.31 \\
Aug & 0.89 & 0.88 & 0.89 & 0.90 & 0.93 & 0.96 & 1.00 & 1.08 & 1.17 & 1.38 \\
Sep & 0.88 & 0.88 & 0.89 & 0.91 & 0.96 & 0.96 & 1.00 & 1.15 & 1.33 & 1.37 \\
Oct & 0.92 & 0.93 & 0.92 & 0.92 & 0.94 & 0.96 & 1.00 & 1.07 & 1.28 & 1.60 \\
Nov & 0.96 & 1.02 & 1.00 & 0.96 & 0.93 & 0.97 & 1.00 & 1.04 & 1.14 & 1.34 \\
Dec & 0.97 & 1.05 & 1.03 & 1.06 & 1.00 & 0.96 & 0.86 & 0.91 & 1.00 & 1.10 \\
\hline
\end{tabular}

Based on the above results, the ratio of $\mathrm{WVC}_{\mathrm{ftd}}$ to the $\mathrm{PWV}$ was computed to have an estimate of the relative input from altitudes higher than the highest altitude of observed data used here. The input from $9.5-30.0 \mathrm{~km}$ is less than $1 \%$ of the PWV.

In Table 4 the inputs of $\mathrm{WVC}_{\text {obs }}(h)$ from $4.5 \mathrm{~km}$ to $9.5 \mathrm{~km}$ and from $4.5-5.0 \mathrm{~km}$ are given (in millimeter of the column of water). We also list the $\mathrm{WVC}_{\mathrm{obs}}(h)$ relative to the $\mathrm{PWV}_{\mathrm{obs}}$, which are values integrated from $2.0 \mathrm{~km}$. These ratios are given in Table 4 in parentheses. The ratios for $4.5-9.5 \mathrm{~km}$ lie between $20 \%$ and $29 \%$ for $0 \mathrm{~h}$ and $15 \%$ and $25 \%$ for $12 \mathrm{~h}$, with the highest values in Spring and Summer. On the other hand, the relative input from $4.5-5.0 \mathrm{~km}$ (also given in Table 4 in parentheses) lies between $4 \%$ and $8 \%$ of the PWV. This means that this input amounts to about a third part of the input from $4.5-9.5 \mathrm{~km}$.

The above results show that the integration of the exponential function $\mathrm{WVC}_{\mathrm{ftd}}(h)$ between different altitudes of interest for SNV leads to values that do not considerably differ from the observed ones. On the other hand, there is a linear relation 

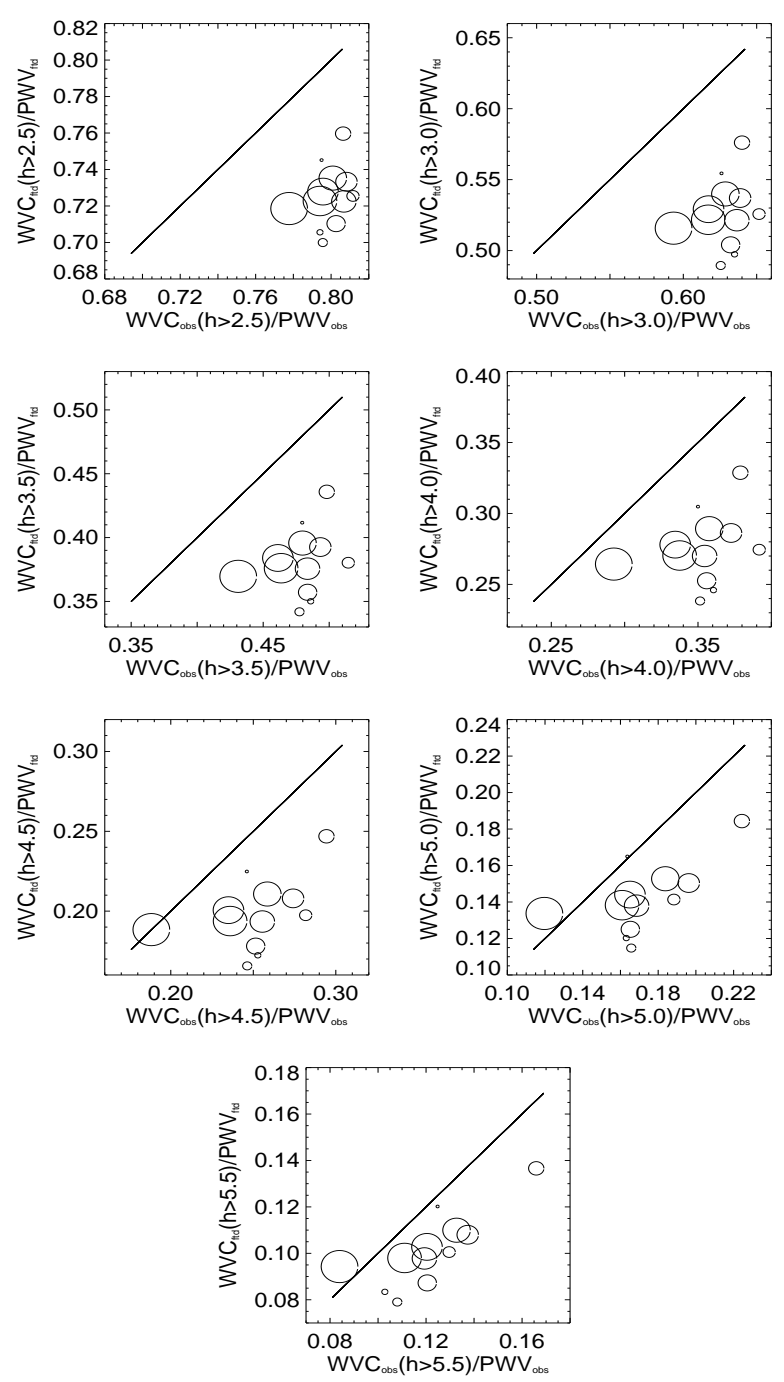

Fig. 6. $\mathrm{WVC}_{\text {ftd }}$ vs. the $\mathrm{WVC}_{\text {obs }}$ for $h \geq h_{\text {low }}$ for $h_{\text {low }}$ from $2.0 \mathrm{~km}$ (upper left panel) to $5.5 \mathrm{~km}$ (lower panel) for data at $0 \mathrm{~h}$.

between the opacity at $210 \mathrm{GHz}\left(\tau_{210}\right)$ and the PWV, given by $\mathrm{PWV}=19.48 \times \tau_{210}-0.3062$ (Otárola et al. 2009) and for $225 \mathrm{GHz}$, given by PWV $=21.422 \times \tau_{225}-0.296$ (Otárola et al. 2010). Because the input from $h \geq 9.5 \mathrm{~km}$, computed with $f t d$ values, is $\leq 1 \%$ of the $\mathrm{PWV}_{\mathrm{ftd}}$, it is expected that the estimate of $\tau_{225}$ using observed data up to $9.5 \mathrm{~km}$ will not considerably differ from that with data including higher altitudes.

Equation (1) shows that $T_{\mathrm{DP}}$ depends on the local $T$ and RH. The pressure due to the water vapor, $P_{\mathrm{H}_{2} \mathrm{O}}$, is related to $T_{\mathrm{DP}}$ by the exponential function given in Eq. (2). The $\mathrm{WVC}_{\mathrm{SNV}}$ computed from $\mathrm{P}_{\mathrm{H}_{2} \mathrm{O}}$ (i.e., the local $\mathrm{WVC}$ ) is linearly related to this.

Common date and hour data at the meteorological station and at the $225 \mathrm{GHz}$ radiometer were used, which is our whole sample for the analysis of the relation between local parameters and the opacity measured at the radiometer. For this sample, the correlation between $\log \left(\tau_{225}\right)$ and $T_{\mathrm{DP}}$ (Fig. 8) and of $\log \left(\tau_{225}\right)$ with $P_{\mathrm{H}_{2} \mathrm{O}}$ (Fig. 9) and also between $\log \left(\tau_{225}\right)$ and $\mathrm{WVC}_{\mathrm{SNV}}$ are given in Cols. 2-7 of Tables 5 and 6. The plot of $\tau_{225}$ versus $\mathrm{WVC}_{\mathrm{SNV}}$ is very similar to that for $P_{\mathrm{H} 2 \mathrm{O}}$ because these two parameters are related linearly. The correlations between $\tau_{225}$ and $T_{\mathrm{DP}}$ and $P_{\mathrm{H} 2 \mathrm{O}}$ and $\mathrm{WVC}_{\mathrm{SNV}}$ were also estimated for data of three consecutive months (e.g., January, February, and March) of the three years. The resulting values are also given in Tables 5 and 6 ,
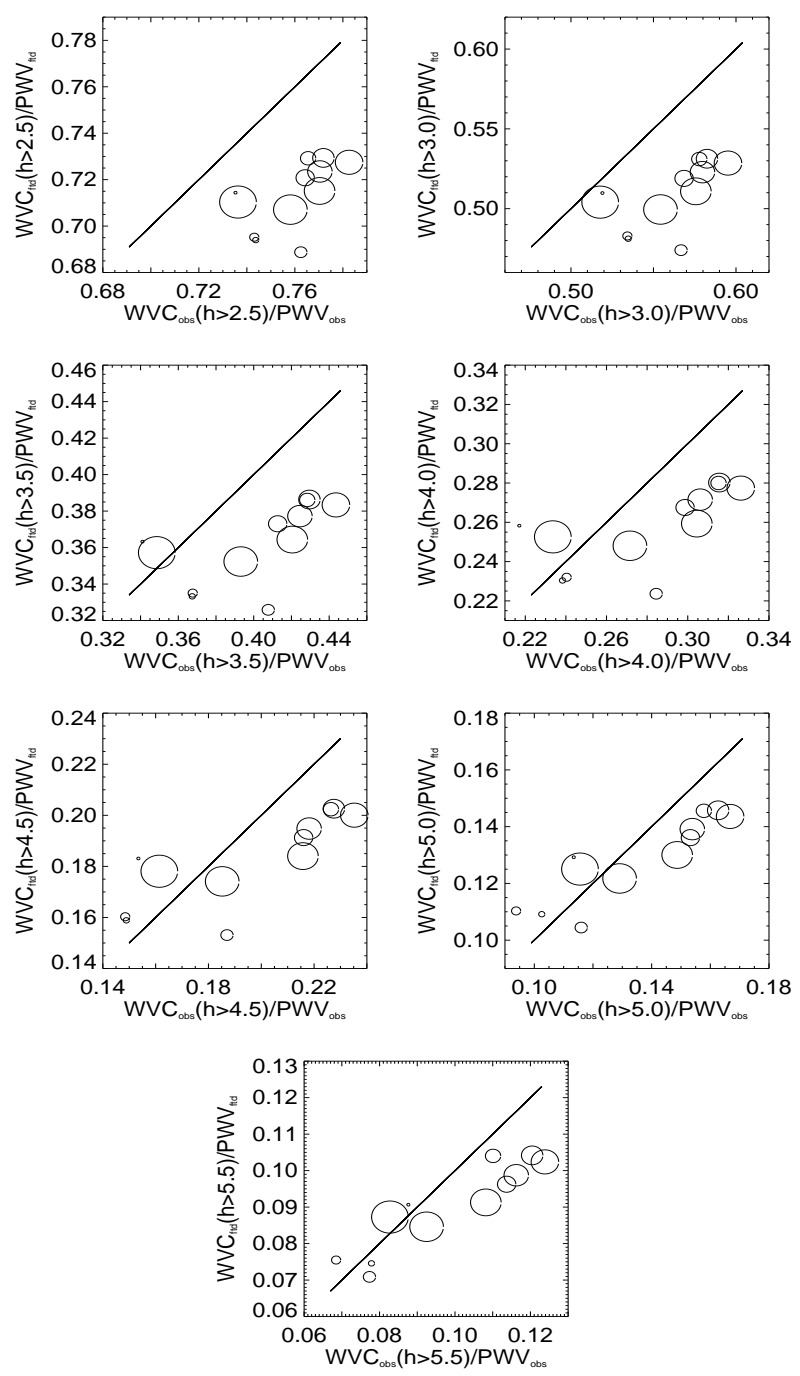

Fig. 7. Same as Fig. 6 for data taken at $12 \mathrm{~h}$.

where the three-month period is denoted with the name of the middle month. We refer to these data as monthly values.

The correlations, estimated with the whole sample data, of $\tau_{225}$ and the opacities from local values $\left(\tau_{\mathrm{DP}}, \tau_{\mathrm{PH} 2 \mathrm{O}}\right.$ and $\left.\tau_{\mathrm{WVC}}\right)$ are given in the first row of Cols. 5-7 of Tables 5 and 6 . In the same tables we also list the correlations for the monthly values. These correlations and those for the whole sample are in the range of $\sim 0.6$ to 0.8 . The highest values occur in Boreal Autumn and Winter. These correlations allow us to propose a functional relation between each pair of the involved parameters, as shown below.

In the following text, we refer to the opacity estimated using $T_{\mathrm{DP}}$ as $\tau_{\mathrm{DP}}$ and to those estimated with $P_{\mathrm{H} 2 \mathrm{O}}$ and $\mathrm{WVC}_{\mathrm{SNV}}$ as $\tau_{\mathrm{PH} 2 \mathrm{O}}$ and $\tau_{\mathrm{WVC}}$, respectively. Based on the relation between $\log \left(\tau_{225}\right)$ and $T_{\mathrm{DP}}$ (Fig. 8), the next function is proposed to express the opacity in terms of $T_{\mathrm{DP}}$,

$\tau_{\mathrm{DP}}=\tau_{0 \mathrm{DP}} \times e^{T_{\mathrm{DP}} / T_{\mathrm{DP} 0}}$,

where $\tau_{0 \mathrm{DP}}$ and $T_{\mathrm{DP} 0}$ are the coefficients that depend on the fit to the observed data (Fig. 8). We proceed in the same way for $P_{\mathrm{H} 2 \mathrm{O}}$ (Fig. 9),

$\tau_{\mathrm{H} 2 \mathrm{O}}=\tau_{0 \mathrm{PH} 2 \mathrm{O}} \times e^{P_{\mathrm{H} 2 \mathrm{O}} / P_{\mathrm{H} 2 \mathrm{OO}}}$,

where $\tau_{0 \mathrm{H} 2 \mathrm{O}}$ and $P_{\mathrm{H} 2 \mathrm{O} 0}$ are the coefficients obtained from the fit. Similarly, we estimated the $\tau_{\mathrm{WVC}}$ based on data of the $\mathrm{WVC}_{\mathrm{SNV}}$ 
Table 4. Input of $\mathrm{WVC}_{\mathrm{obs}}$ to the $\mathrm{PWV}_{\text {obs }}$ for Sierra Negra from the 4.5$9.5 \mathrm{~km}$ and $4.5-5.0 \mathrm{~km}$ altitude intervals, given in millimeter.

\begin{tabular}{lllll}
\hline \hline & \multicolumn{3}{c}{$\left(\mathrm{WVC}_{\mathrm{obs}}\left(h_{\mathrm{low}}-h_{\mathrm{up}}\right) / \mathrm{PWV}\right.$ obs } \\
\hline & \multicolumn{3}{c}{$0 \mathrm{~h}$} & $12 \mathrm{~h}$ \\
\hline \multirow{2}{*}{ Time } & m.5-9.5 & $4.5-5.0$ & $4.5-9.5$ & $4.5-5.0$ \\
\hline Jan & 2.33 & 0.65 & 1.41 & 0.39 \\
& $(0.206)$ & $(0.057)$ & $(0.153)$ & $(0.042)$ \\
Feb & 2.38 & 0.74 & 1.89 & 0.46 \\
& $(0.223)$ & $(0.069)$ & $(0.195)$ & $(0.047)$ \\
Mar & 2.94 & 0.87 & 1.92 & 0.61 \\
& $(0.238)$ & $(0.070)$ & $(0.178)$ & $(0.056)$ \\
Apr & 3.90 & 1.07 & 2.63 & 0.84 \\
& $(0.274)$ & $(0.075)$ & $(0.214)$ & $(0.068)$ \\
May & 4.67 & 1.22 & 3.60 & 0.98 \\
& $(0.286)$ & $(0.075)$ & $(0.235)$ & $(0.064)$ \\
Jun & 5.11 & 1.39 & 4.75 & 1.28 \\
& $(0.262)$ & $(0.071)$ & $(0.244)$ & $(0.066)$ \\
Jul & 5.17 & 1.37 & 4.42 & 1.16 \\
& $(0.272)$ & $(0.072)$ & $(0.239)$ & $(0.063)$ \\
Aug & 5.33 & 1.46 & 4.52 & 1.18 \\
& $(0.266)$ & $(0.073)$ & $(0.244)$ & $(0.064)$ \\
Sep & 5.96 & 1.66 & 5.08 & 1.39 \\
& $(0.268)$ & $(0.075)$ & $(0.249)$ & $(0.068)$ \\
Oct & 5.22 & 1.45 & 4.58 & 1.24 \\
& $(0.256)$ & $(0.071)$ & $(0.241)$ & $(0.065)$ \\
Nov & 3.98 & 1.15 & 3.00 & 0.86 \\
& $(0.228)$ & $(0.066)$ & $(0.210)$ & $(0.060)$ \\
Dec & 2.61 & 0.76 & 2.04 & 0.54 \\
& $(0.204)$ & $(0.059)$ & $(0.175)$ & $(0.046)$ \\
\hline
\end{tabular}

Notes. In parentheses we list the ratio of these $\mathrm{WVC}_{\mathrm{obs}}$ values to the $\mathrm{PWV}_{\mathrm{obs}}$ (which is integrated from $2.0 \mathrm{~km}$ ).
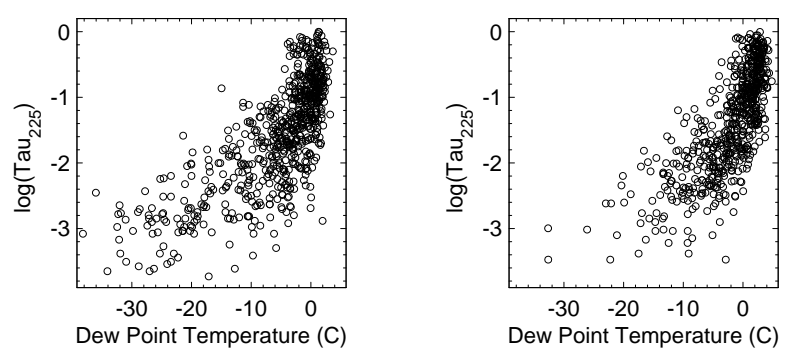

Fig. 8. The opacity $\tau$ measured with a radiometer at $225 \mathrm{GHz}$ vs. the temperature of the dew point, $T_{\mathrm{DP}}$, measured with a meteorological station at the summit of SNV. The coefficients for the equation $\tau\left(T_{\mathrm{DP}}\right)=\tau_{0} e^{T_{\mathrm{DP}} / T_{\mathrm{DP} 0}}$ are given in Tables 7 an 8 . Left side: for $0 \mathrm{~h}$, and right side: same as the left side for $12 \mathrm{~h}$ data.

as follows:

$\tau_{\mathrm{WVC}}=\tau_{0 \mathrm{WVC}} \times e^{\mathrm{WVC}_{\mathrm{SNV}} / \mathrm{WVC}_{\mathrm{SNV} 0}}$,

with $\tau_{0 \mathrm{WVC}}$ and $\mathrm{WVC}_{\mathrm{SNV} 0}$, the corresponding coefficients. This means that for each parameter $\left(T_{\mathrm{DP} 0}, P_{\mathrm{H} 2 \mathrm{O}}\right.$, and $\left.\mathrm{WVC}_{\mathrm{SNV} 0}\right)$, a pair of coefficients is obtained based on the fit to the whole sample (simultaneously observed with the radiometer and the meteorological station). These values are given in the first row of Tables 7 and 8 . With these coefficients we calculated the expected opacity $\tau_{\mathrm{DP}}$ using $T_{\mathrm{DP}}$ and $\tau_{\mathrm{PH} 2 \mathrm{O}}$ and $\tau_{\mathrm{WVC}}$ using $P_{\mathrm{H} 2 \mathrm{O}}$ and $\mathrm{WVC}_{\mathrm{SNV}}$, respectively. In Fig. 10 we plot $\tau_{225}$ against $\tau_{\mathrm{DP}}$ for the coefficients estimated over the whole sample (circles). We
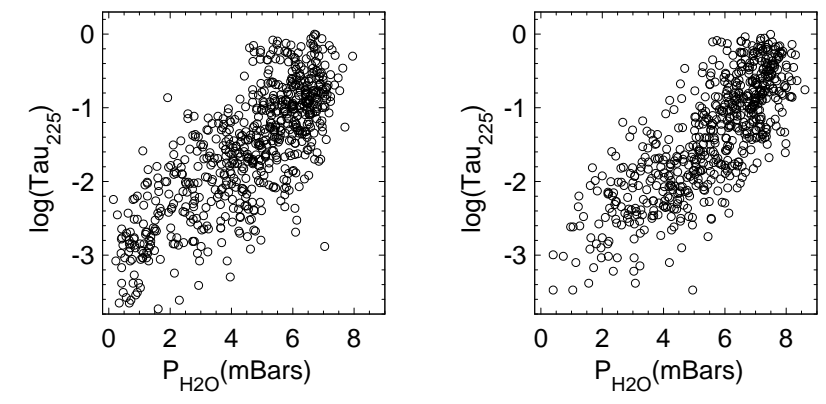

Fig. 9. Same as Fig. 8, here for the opacity measured with a radiometer at $225 \mathrm{GHz}$ vs. the pressure of the water vapor at the site. Left side: for $0 \mathrm{~h}$, and right side: same as the left side for $12 \mathrm{~h}$ data.

Table 5. Correlations between local parameters and $\tau_{225}$ and between the opacity estimated with the local parameters and the measured opacity, $\tau_{225}$, for $0 \mathrm{~h}$.

\begin{tabular}{lcccccc}
\hline \hline \multicolumn{5}{c}{ Parameter pairs } \\
\hline Time & $\left(T_{\mathrm{DP}}\right.$, & $\left(P_{\mathrm{H} 2 \mathrm{O} 0}\right.$, & $\left(\mathrm{WVC}_{\mathrm{SNV}}\right.$, & $\left(\tau_{\mathrm{DP}}\right.$, & $\left(\tau_{\mathrm{PH} 2 \mathrm{O}}\right.$, & $\left(\tau_{\mathrm{WVC}}\right.$, \\
\hline \multirow{2}{*}{$\left.\tau_{225}\right)$} & $\left.\tau_{225}\right)$ & $\left.\tau_{225}\right)$ & $\left.\tau_{225}\right)$ & $\left.\tau_{225}\right)$ & $\left.\tau_{225}\right)$ \\
Jan & 0.74 & 0.77 & 0.77 & 0.66 & 0.66 & 0.67 \\
Feb & 0.62 & 0.69 & 0.69 & 0.57 & 0.64 & 0.65 \\
Mar & 0.67 & 0.72 & 0.72 & 0.60 & 0.64 & 0.65 \\
Apr & 0.65 & 0.70 & 0.71 & 0.55 & 0.55 & 0.56 \\
May & 0.60 & 0.64 & 0.64 & 0.50 & 0.49 & 0.50 \\
Jun & 0.65 & 0.65 & 0.62 & 0.52 & 0.53 & 0.53 \\
Jul & 0.69 & 0.69 & 0.66 & 0.55 & 0.54 & 0.54 \\
Aug & 0.73 & 0.72 & 0.73 & 0.59 & 0.58 & 0.59 \\
Sep & 0.80 & 0.80 & 0.80 & 0.65 & 0.58 & 0.59 \\
Oct & 0.78 & 0.81 & 0.81 & 0.68 & 0.69 & 0.65 \\
Nov & 0.76 & 0.79 & 0.79 & 0.67 & 0.68 & 0.69 \\
Dec & 0.72 & 0.75 & 0.75 & 0.62 & 0.64 & 0.65 \\
\hline
\end{tabular}

Table 6. Same as Table 5 for $12 \mathrm{~h}$.

\begin{tabular}{lcccccc}
\hline \hline \multicolumn{5}{c}{ Parameter pairs } \\
\hline Time & $\left(T_{\mathrm{DP}}\right.$, & $\left(P_{\mathrm{H} 2 \mathrm{O} 0}\right.$, & $\left(\mathrm{WVC}_{\mathrm{SN}}\right.$, & $\left(\tau_{\mathrm{DP}}\right.$, & $\left(\tau_{\mathrm{PH} 2 \mathrm{O}}\right.$, & $\left(\tau_{\mathrm{WVC}}\right.$, \\
\hline \multirow{2}{*}{$\left.\tau_{225-2015}\right)$} & 0.74 & 0.78 & 0.79 & 0.70 & 0.71 & 0.71 \\
Jan & 0.64 & 0.67 & 0.67 & 0.57 & 0.60 & 0.60 \\
Feb & 0.66 & 0.68 & 0.68 & 0.59 & 0.61 & 0.62 \\
Mar & 0.66 & 0.67 & 0.67 & 0.57 & 0.57 & 0.57 \\
Apr & 0.65 & 0.65 & 0.66 & 0.52 & 0.49 & 0.50 \\
May & 0.62 & 0.65 & 0.66 & 0.55 & 0.54 & 0.55 \\
Jun & 0.57 & 0.58 & 0.59 & 0.51 & 0.50 & 0.51 \\
Jul & 0.65 & 0.65 & 0.66 & 0.60 & 0.59 & 0.60 \\
Aug & 0.68 & 0.68 & 0.69 & 0.64 & 0.64 & 0.65 \\
Sep & 0.76 & 0.79 & 0.80 & 0.65 & 0.64 & 0.65 \\
Oct & 0.79 & 0.82 & 0.83 & 0.72 & 0.72 & 0.73 \\
Nov & 0.74 & 0.78 & 0.79 & 0.70 & 0.71 & 0.71 \\
Dec & 0.69 & 0.74 & 0.74 & 0.68 & 0.69 & 0.70 \\
\hline
\end{tabular}

also used data of three consecutive months, as described above, and estimated for them the $\tau_{0 \mathrm{DP}}$ and $T_{\mathrm{DP} 0}$ coefficients of Eq. (4). The resulting coefficients are taken as representative of the middle month of the period (Tables 7 and 8 ). The opacities computed 
Table 7. Coefficients of Eqs. (4)-(6) obtained for data taken at $0 \mathrm{~h}$ in 2013-2015.

\begin{tabular}{lcccccc}
\hline \hline Time & $\tau_{0 \mathrm{DP}}$ & $T_{\mathrm{DP} 0}$ & $\tau_{0 \mathrm{PH} 2 \mathrm{O}}$ & $P_{\mathrm{H} 2 \mathrm{O} 0}$ & $\tau_{0 \mathrm{WVC}}$ & $\mathrm{WVC}_{\mathrm{SNV} 0}$ \\
\hline 2013-2015 & 0.324 & 13.36 & 0.046 & 2.99 & 0.046 & 1.15 \\
Jan & 0.198 & 18.26 & 0.038 & 3.01 & 0.038 & 1.17 \\
Feb & 0.233 & 15.57 & 0.035 & 2.76 & 0.035 & 1.07 \\
Mar & 0.247 & 14.95 & 0.038 & 3.01 & 0.038 & 1.16 \\
Apr & 0.326 & 13.67 & 0.054 & 3.28 & 0.054 & 1.26 \\
May & 0.358 & 13.64 & 0.071 & 3.77 & 0.071 & 1.45 \\
Jun & 0.415 & 12.09 & 0.081 & 3.76 & 0.080 & 1.44 \\
Jul & 0.409 & 11.22 & 0.074 & 3.60 & 0.073 & 1.38 \\
Aug & 0.419 & 11.93 & 0.083 & 3.79 & 0.082 & 1.45 \\
Sep & 0.371 & 12.19 & 0.054 & 3.18 & 0.054 & 1.22 \\
Oct & 0.315 & 14.29 & 0.048 & 3.16 & 0.048 & 1.22 \\
Nov & 0.286 & 15.65 & 0.051 & 3.30 & 0.051 & 1.27 \\
Dec & 0.263 & 17.17 & 0.053 & 3.44 & 0.053 & 1.33 \\
\hline
\end{tabular}

Table 8. Coefficients of Eqs. (4)-(6) for 2013-2015 data, obtained at $12 \mathrm{~h}$.

\begin{tabular}{lcccccc}
\hline \hline Time & $\tau_{0 \mathrm{DP}}$ & $T_{\mathrm{DP} 0}$ & $\tau_{0 \mathrm{PH} 2 \mathrm{O}}$ & $P_{\mathrm{H} 2 \mathrm{O} 0}$ & $\tau_{0 \mathrm{WVC}}$ & $\mathrm{WVC}_{\mathrm{SNV} 0}$ \\
\hline 2013-2015 & 0.317 & 9.65 & 0.037 & 2.89 & 0.036 & 1.10 \\
Jan & 0.206 & 16.04 & 0.045 & 3.61 & 0.045 & 1.39 \\
Feb & 0.224 & 13.88 & 0.042 & 3.40 & 0.041 & 1.30 \\
Mar & 0.241 & 11.90 & 0.045 & 3.61 & 0.044 & 1.37 \\
Apr & 0.286 & 10.46 & 0.045 & 3.37 & 0.044 & 1.28 \\
May & 0.327 & 9.29 & 0.046 & 3.24 & 0.045 & 1.22 \\
Jun & 0.367 & 8.33 & 0.060 & 3.44 & 0.057 & 1.28 \\
Jul & 0.347 & 6.78 & 0.042 & 2.96 & 0.040 & 1.10 \\
Aug & 0.375 & 7.09 & 0.050 & 3.07 & 0.047 & 1.14 \\
Sep & 0.359 & 7.85 & 0.029 & 2.53 & 0.028 & 0.96 \\
Oct & 0.353 & 7.90 & 0.030 & 2.56 & 0.029 & 0.97 \\
Nov & 0.315 & 9.70 & 0.038 & 2.91 & 0.038 & 1.11 \\
Dec & 0.295 & 10.57 & 0.041 & 3.04 & 0.041 & 1.16 \\
\hline
\end{tabular}
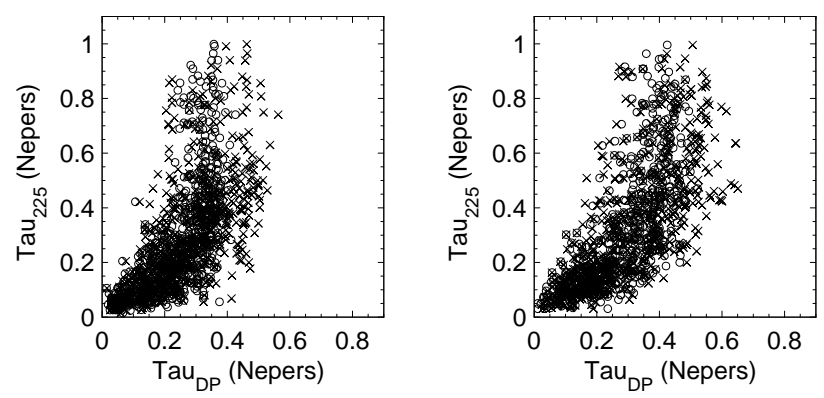

Fig. 10. Opacity measured with the radiometer at $225 \mathrm{GHz}, \tau_{225}$, vs. the opacity estimated with $T_{\mathrm{DP}}$. Left side: for $0 \mathrm{~h}$, and right side: same as the left side for $12 \mathrm{~h}$.

with these values, $\tau_{\mathrm{DP}}$, are shown with crosses in Fig. 10 . The same analysis was made for the $P_{\mathrm{H} 2 \mathrm{O}}$ data (Fig. 11) and also for $\mathrm{WVC}_{\text {SNV. }}$.

The correlation between the $\tau_{225}$ and $\tau_{\mathrm{DP}}$ using meteorological data of the whole sample, but using for each value the corresponding monthly coefficients, given in Tables 7 and 8 (plotted with crosses in Fig. 10) is 0.67 for $0 \mathrm{~h}$, and 0.72 for $12 \mathrm{~h}$. On the other hand, computing the opacities from the local values of the whole sample, with no distinction of the month they belong to
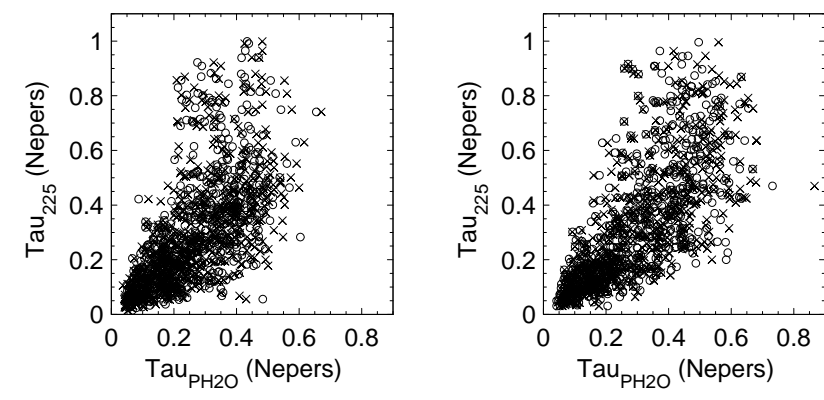

Fig. 11. Same as Fig. 10 for the opacity measured with the radiometer at $225 \mathrm{GHz}, \tau_{225}$, vs. the opacity estimated with $P_{\mathrm{H} 2 \mathrm{O}}$. Left side: for $0 \mathrm{~h}$, and right side: for $12 \mathrm{~h}$.

(circles in Fig. 10), leads to correlations 0.66 for $0 \mathrm{~h}$ and 0.70 for $12 \mathrm{~h}$. Similarly, the correlations of $\tau_{225}$ with $\tau_{\mathrm{PH} 2 \mathrm{O}}$ throughout the whole sample, using for the computation of $\tau_{\mathrm{PH} 2 \mathrm{O}}$ the corresponding monthly coefficients for each $P_{\mathrm{H} 2 \mathrm{O}}$ (plotted with crosses in Fig. 11), are 0.68 for $0 \mathrm{~h}$ and 0.72 for $12 \mathrm{~h}$, and for the fits to the whole sample, regardless of the month (circles in Fig. 11), they are 0.66 and 0.71 , respectively. The correlations for $\tau_{\mathrm{WVC}}$ computed using the monthly values are 0.68 for $0 \mathrm{~h}$ and 0.73 for $12 \mathrm{~h}$, and for the whole sample, they are 0.67 and 0.71 , respectively. This means that the correlation increases by estimating the opacity with the monthly values of the coefficients. However, the increase is small, indicating that the estimation of $\tau_{225}$ with these values is not considerably improved by using the coefficients of the whole sample.

In the estimation of the $\tau_{225}$, with the variables $T_{\mathrm{DP}}, P_{\mathrm{H} 2 \mathrm{O}}$ and $\mathrm{WVC}_{\mathrm{SNV}}$, the uncertainty is low for low values of $\tau_{\mathrm{DP}}, \tau_{\mathrm{PH} 2 \mathrm{O}}$, and $\tau_{\mathrm{WVC}}$ and grows as they grow. The corrected $\tau_{\mathrm{DP}}$, including an estimation of the uncertainty $\tau_{225 \mathrm{DP}}$, is given as follows:

$$
\begin{aligned}
& \tau_{225 \mathrm{DP}}=\left(1.06 \tau_{\mathrm{DP}}+0.01\right) \pm\left(0.40 \tau_{\mathrm{DP}}+0.04\right) \text { for } 00 \mathrm{~h} \\
& \tau_{225 \mathrm{DP}}=\left(1.24 \tau_{\mathrm{DP}}-0.02\right) \pm\left(0.44 \tau_{\mathrm{DP}}+0.02\right) \text { for } 12 \mathrm{~h},
\end{aligned}
$$

the corrected $\tau_{\mathrm{PH} 2 \mathrm{O}}$ opacity, also including the uncertainty, is

$$
\begin{aligned}
& \tau_{225 \mathrm{PH} 2 \mathrm{O}}=\left(0.81 \tau_{\mathrm{PH} 20}+0.08\right) \pm\left(0.35 \tau_{\mathrm{PH} 2 \mathrm{O}}+0.05\right) \text { for } 00 \mathrm{~h} \\
& \tau_{225 \mathrm{PH} 2 \mathrm{O}}=\left(0.92 \tau_{\mathrm{PH} 20}+0.05\right) \pm\left(0.20 \tau_{\mathrm{PH} 2 \mathrm{O}}+0.08\right) \text { for } 12 \mathrm{~h},
\end{aligned}
$$

and that estimated using $\mathrm{WVC}_{\mathrm{SNV}}$ is

$$
\begin{aligned}
& \tau_{225 \mathrm{WVC}}=\left(0.99 \tau_{\mathrm{WVC}}+0.04\right) \pm\left(0.28 \tau_{\mathrm{WVC}}+0.07\right) \text { for } 00 \mathrm{~h} \\
& \tau_{225 \mathrm{WVC}}=\left(0.95 \tau_{\mathrm{WVC}}+0.04\right) \pm\left(0.20 \tau_{\mathrm{WVC}}+0.08\right) \text { for } 12 \mathrm{~h} .
\end{aligned}
$$

These expressions allow us to estimate the expected opacity at $225 \mathrm{GHz}$ based on the local meteorological parameters $\left(T_{\mathrm{DP}}\right.$, $P_{\mathrm{H} 2 \mathrm{O}}$, or $\left.\mathrm{WVC}_{\mathrm{SNV}}\right)$ using the values given in Tables 7 and 8 , and substituting them into Eqs. (7)-(9). The estimation of $\tau_{225}$ is good for the opacities of interest (lower than 0.30 Nepers), with an uncertainty smaller than 0.16 Nepers.

\section{Conclusions}

A study of the Sierra Negra $\mathrm{WVC}_{\text {obs }}(h)$ altitude profile was made using radiosonde data. Exponential functions were fit to the obtained profiles, $\mathrm{WVC}_{\mathrm{ftd}}(h)$. The integration of $\mathrm{WVC}_{\mathrm{ftd}}(h)$ between 9.5 and $30.0 \mathrm{~km}$ shows that the input from this range to the PWV is lower than $1 \%$, whereas the input from $4.5 \mathrm{~km} \leq h \leq$ $9.5 \mathrm{~km}$ to the PWV takes values $15 \% \leq \mathrm{WVC}_{\mathrm{obs}} \leq 29 \%$ during 
the year. The estimated WVC at $4.5-5.0 \mathrm{~km}$ gives between $4 \%$ and $8 \%$ of the PWV. This means that it accounts for a large fraction of the total amount of WVC from $4.5 \mathrm{~km} \leq h \leq 9.5 \mathrm{~km}$. This type of studies can be conducted for sites that are candidates for astronomical observations, where no radiosondes are released but that are located between two or more radiosonde stations. The results may allow estimating $\tau$ for millimeter wavelengths using local meteorological parameters. The correlations between $\tau_{225}$, the opacity measured at $\mathrm{SNV}$ with $T_{\mathrm{DP}}, P_{\mathrm{H} 2 \mathrm{O}}$, and $\mathrm{WVC}_{\mathrm{SNV}}$ indicates that it is possible to estimate $\tau_{225}$ based on these parameters with uncertainties smaller than 0.16 Nepers for $\tau \leq 0.30$ Nepers.

Acknowledgements. We would like to thank the team that supports the database of the University of Wyoming for radiosonde data. Also, we would like to thank to Carrasco-Martínez J.L., Ramos-Benítez V.R. of the Comisión Nacional del Agua, México and to the staff of the Mexico City station of radiosondes, who kindly have shown us the release of sondes and gave us information about their data. We also thank the anonymous referee for his/her suggestions, which help us to improve this work.

\section{References}

Alduchov, O., \& Eskridge, R. 1996, J. Appl. Meteorol., 35, 601

Carreón-Sierra, S., Salcido, A., Castro, T., \& Celada-Murillo, A.-T. 2015 , Atmosphere, 6, 1006
Cassiano, M. M., Cornejo, Espinoza D., Raulin, J.-P., \& Giménez de Castro, C. G. 2018, J. Atmos. S-T Phys., 168, 32

Delgado, G., Otarola, A., Belitsky, V., \& Urbain, D. 1999, NRAO, 271, 1

Ferrusca, D., \& Contreras, J. 2014, Proc. SPIE, 9147, 914730

Hills, R., \& Richer, J. 2000, ALMA Memo, 303, 1

Giordano, C., Vernin, J., VazquezRamio, H., et al. 2013, MNRAS, 430, 3102

Giovanelli, R., Haynes, M. P., Salzer, J. J., et al. 2001, PASP, 113, 803

Florian, K., Eloy, R., Cristina, R. L., et al. 2012, SPIE, 8446, 93

Lawrence, M. G. 2005, Bull. Amer. Meteor. Soc., 86, 225

Marín, J. C., Pozo, D., \& Curé, M. 2015, A\&A, 573, A41

Otárola, A., Hiriart, D., \& Pérez-León, J. E. 2009, Rev. Mex. Astron. Astrofís., 45,161

Otárola, A., Travouillon, T., Schöck, E. S., et al. 2010, PASP, 122, 470

Pérez-Jórdan, G., Castro-Almazán, J. A., Muñoz-Tuñón, C., Codina, B., \& Vernin, J. 2015, MNRAS, 452, 1992

Pérez-Jordán, G., Castro-Almazán, J. A., \& Muñoz-Tuñón, C. 2018, MNRAS, 477, 5477

Pozo, D., Marín, J. C., Illanes, L., Curé, M., \& Rabanus, D. 2016, MNRAS, 459, 419

Qin, Z., Karnieli, A., \& Berliner, P. 2001, Int. J. Remote Sens., 18, 3719

Thomas, S. R., Martínez-Alvarado, O., Drew, D., \& Bloomfield, H. 2020, Int. J. Climatol., 1 (in press)

Turchi, A., Masciadri, E., Kerber, F., \& Martelloni, G. 2018, MNRAS, 482, 206

Turchi, A., Masciadri, E., Pathak, P., \& Kasper, M. 2020, MNRAS, 497, 4910

Turner, D. D., Clough, S. A., Liljegren, J. C., et al. 2007, IEEE Trans. Geosci. Remote Sens., 11, 3680

Vogelmann, H., \& Trickl, T. 2008, Appl. Opt., 47, 2116

Zeballos, M., Ferrusca, D., \& Contreras, J. 2016, Proc. SPIE, 9906, 99064U 